\title{
IS STONE RADIODENSITY A USEFUL PARAMETER FOR PREDICTING OUTCOME OF EXTRACORPOREAL SHOCKWAVE LITHOTRIPSY FOR STONES $\leq 2$ CM?
}

\author{
MINA S. KRISHNAMURTHY, PAUL G. FERUCCI, NOEL SANKEY, PARAMJIT S. \\ CHANDHOKE \\ Department of Surgery (Urology) and Medicine (Renal Diseases), University of Colorado Health Sciences \\ Center and Kidney Stone Center of the Rocky Mountains, Denver, Colorado, USA
}

\begin{abstract}
Purpose: Several factors determine the success of extracorporeal shockwave lithotripsy (SWL) for kidney stones: stone size, stone location within the collecting system, stone type, and the SWL machine used. It has been suggested that stone radiodensity, as determined either by plain radiography or computed tomography attenuation values, may be an independent predictor of SWL success. We examined the outcome of SWL for solitary stones less than or equal to $2 \mathrm{~cm}$ located within the renal pelvis, based on their radiodensity.

Material and Methods: 211 patients with solitary renal pelvic stones measuring less than or equal to $2 \mathrm{~cm}$ were treated on a Dornier Doli 50 lithotriptor under general anesthesia. The radiodensity of the stone was determined to be either less than, equal to, or greater than the radiodensity of the ipsilateral $12^{\text {th }}$ rib. Stone-free rates (SFR) were determined at 3 months by kidney, ureters and bladder (KUB) plain X-rays. Patients requiring re-treatment or auxiliary procedures were considered failures of SWL.

Results: Follow-up SFR information was available in all 211 patients. Stone composition was available in $158(75 \%)$ treated patients, but no correlation was found between stone radiodensity and stone composition. For stones $\leq 10 \mathrm{~mm}$ within the renal pelvis, the SFRs were similar (71 to $74 \%$ regardless of stone radiodensity). For stones between 11 and $20 \mathrm{~mm}$, the SFR was $60 \%$ if the stone had a radiodensity $>12^{\text {th }}$ rib compared to a SFR of $71 \%$ if the stone radiodensity was $\leq 12^{\text {th }}$ rib. However, these differences in SFRs were not statistically significant.

Conclusions: On the Doli machine, stone radiodensity alone does not predict lithotripsy treatment outcome for stones $\leq 1 \mathrm{~cm}$ within the renal pelvis. This parameter is probably only useful as the stone size becomes larger than $1 \mathrm{~cm}$, and should be used in conjunction with other stone parameters to select appropriate therapy.
\end{abstract}

Key words: kidney calculi; calcium; densitometry, X-ray; extracorporeal shock wave lithotripsy; treatment outcome

Int Braz J Urol. 2005; 31: 3-9

\section{INTRODUCTION}

Several factors determine the success of extracorporeal shockwave lithotripsy (SWL): stone size, stone location, stone composition, and the type of SWL machine. For radiopaque stones $\leq 20 \mathrm{~mm}$ within the renal pelvis, SWL is the initial treatment of choice. In most patients, however, the true composition of 
the stone is unknown at the time of the SWL. Radiopaque stones of this size are likely to be some admixture of calcium - calcium oxalate $(\mathrm{CaOx})$ monohydrate, $\mathrm{CaOx}$ dihydrate, or calcium phosphate. Uric acid stones are generally radiolucent, struvite stones are usually greater than $2 \mathrm{~cm}$, and cystine stones are rare. To select appropriate stone treatment, it has been suggested that the stone's radiodensity, computed tomography (CT) attenuation value, and shape should also be considered (1). However, good clinical studies to validate these radiographic concepts are lacking.

In a multivariate analysis of various stone parameters, Bon et al. (2) reported that smooth dense stones had a SFR of $33.6 \%$ compared to a $79.4 \%$ SFR for rough, less dense stones as determined by a plain radiograph of the kidneys, ureter, and bladder (KUB). In contrast, Aebreli et al. (3) found no correlation of radiographic stone appearance and SWL treatment outcome. Unfortunately, results were not stratified according to stone size and stone location in either of these reports.

Although CT attenuation values have been proposed to predict stone composition and stone fragility, the variability of attenuation values for calcium containing stones makes this task more difficult (1). The variability of CT attenuation values is also related to different types of CT scanners and the beam collimation width used to perform the study (4). As such, the role of $\mathrm{CT}$ attenuation values in predicting SWL outcome for calcium stones less than $20 \mathrm{~mm}$ in size is still being defined.

We examined the outcome of SWL for solitary stones less than or equal to $2 \mathrm{~cm}$ located within the renal pelvis based on their radiodensity relative to the $12^{\text {th }}$ rib on a preoperative KUB. Unlike CT attenuation values, the information on the stone's relative radiodensity is universally available at the time of SWL.

\section{MATERIALS AND METHODS}

From January 1998 to December 1999, a total of 1,974 patients underwent SWL on the Dornier Doli 50 lithotriptor at the Kidney Stone Center of the Rocky Mountains, Denver, Colorado. Of these 1,974 patients, $211(10 \%)$ met the entry criteria of a solitary stone within the renal pelvis less than or equal to $20 \mathrm{~mm}$. Patients with bilateral stones, multiple stones, radiolucent stones, stones $>20 \mathrm{~mm}$, or stones elsewhere in the collecting system were excluded. Patients were treated on an outpatient basis by various community urologists who comprise the treating panel, under the supervision of the lithotripsy director. All patients received general anesthesia. Pre-operative ureteral stent placement was left to the discretion of the treating urologist and the patient.

Using the pre-operative KUB, the stone radiodensity was determined relative to the radiodensity of the ipsilateral $12^{\text {th }}$ rib. The stone was assigned a value of either less than or equal to the radiodensity of the $12^{\text {th }}$ rib, or greater than the radiodensity of the $12^{\text {th }}$ rib. Stones were also grouped according to size: either $\leq 10 \mathrm{~mm}$, or between 11-20 $\mathrm{mm}$.

The patients were divided into 4 treatment groups based on stone characteristics. Group 1 included 61 patients with stones $\leq 10 \mathrm{~mm}$ and radiodensity $>12^{\text {th }}$ rib. The mean stone size was 7.8 $\pm 0.24 \mathrm{~mm}$. There were 35 patients in Group 2, which comprised patients with a stone size $\leq 10 \mathrm{~mm}$ and a stone radiodensity $\leq 12^{\text {th }}$ rib. The mean stone size was $7.7 \pm 0.36 \mathrm{~mm}$ in Group 2. Group $3(\mathrm{n}=81)$ patients had stones $11-20 \mathrm{~mm}$ in size with a stone radiodensity greater than the $12^{\text {th }}$ rib. Group 4 consisted of 34 patients with stones that were $11-20 \mathrm{~mm}$ in size and stone radiodensity less than the $12^{\text {th }}$ rib. The mean stone size was $14.5 \pm 0.34 \mathrm{~mm}$ and $14.5 \pm 0.44 \mathrm{~mm}$ for Groups 3 and 4 respectively.

The power index (PI) was recorded for each treatment. The PI was calculated by multiplying the products of the number of shocks given by the power level (range 1 to 6 ) at which the shocks were administered.

The stone free rate (SFR) was determined by KUB at 3 months following the treatment. Shockwave lithotripsy was considered a failure if residual stone fragments remained after 3 months or if an auxiliary procedure or a re-treatment was required. Follow-up status was obtained in writing from the referring urologist. Adequate 3-month fol- 
Table 1 - Outcome of shockwave lithotripsy based on stone size and stone radiodensity.

\begin{tabular}{lcccrrr}
\hline Group & $\begin{array}{c}\text { Number } \\
\text { of Patients }\end{array}$ & $\begin{array}{c}\text { Stone } \\
\text { Size (mm) }\end{array}$ & $\begin{array}{c}\text { Stone } \\
\text { Density } \\
(\text { mean } \pm \text { SE) }\end{array}$ & $\begin{array}{c}\text { Mean stone } \\
\text { size (mm) }\end{array}$ & $\begin{array}{c}\text { Power Index } \\
(\text { mean } \pm \text { SE) }\end{array}$ & $\begin{array}{c}\text { Stone Free } \\
\text { Rate }(\%)\end{array}$ \\
\hline 1 & 61 & $\leq 10$ & $>12^{\text {th }}$ rib & $7.8 \pm 0.24$ & $11,868 \pm 375$ & 74 \\
2 & 35 & $\leq 10$ & $\leq 12^{\text {th }}$ rib & $7.7 \pm 0.36$ & $9650 \pm 641$ & 71 \\
3 & 81 & $11-20$ & $>12^{\text {th }}$ rib & $14.5 \pm 0.34$ & $12,958 \pm 290$ & 60 \\
4 & 34 & $11-20$ & $\leq 12^{\text {th }}$ rib & $14.5 \pm 0.44$ & $11,883 \pm 468$ & 71 \\
\hline
\end{tabular}

low-up was available for all patients. Statistical significance of the stone-free rates was evaluated with the chi-square test.

Voided stone fragments were mailed to Dianon Systems, Inc. (Oklahoma City, OK, USA) for stone analysis. Although such reports yielded information on the percentage of various stone components, the primary stone composition was defined as the component containing the highest percentage in the report.

\section{RESULTS}

The stone characteristics and treatment outcomes of the various groups are summarized in Table- 1 . In Group 1, the average PI was $11,868 \pm$ 375 with a SFR of $74 \%$. In Group 2, the average PI was $9650 \pm 641$ with a SFR of $71 \%$. There were no statistically significant differences between the SFRs and PIs of Groups 1 and 2.

For Group 3, the PI was $12,958 \pm 290$ with a SFR of $60 \%$. In Group 4, the average PI was 11,883 \pm 468 with a SFR of $71 \%$. Although Group 3 patients had a slightly higher PI and a lower SFR compared to Group 4 patients, these differences were not statistically significant.

Of the 211 treated patients, stone analysis was available in 158 (75\%). The stone composition, stratified by whether the patient was stone free or not, is shown in Table-2. Approximately two-thirds of the patients had calcium oxalate monohydrate as the predominant stone component. The stone radiodensity was not predictive of stone type or of stone fragility, even when stratified according to stone size. The per- centage of stones that had calcium oxalate monohydrate as their major component was $71 \%, 63 \%, 60 \%$, and $66 \%$ in Groups 1, 2, 3, and 4 respectively (considered not statistically significant).

\section{COMMENTS}

Several factors determine the success of SWL, including stone size, stone location, stone composition, and the type of lithotriptor used for the SWL. SWL is the treatment of choice for stones $\leq 20 \mathrm{~mm}$ within the renal pelvis. Knowledge of the stone composition is an independent variable that may be useful to predict SWL success. However, to date, we have not been able to accurately identify the composition of most stones or reliably predict their fragility based on radiographic appearance prior to SWL (1). A "fragility index" that predicts SWL success based on stone size, stone location, radiographic appearance by KUB, CT attenuation value, and the type of lithotriptor is not available (1).

Dretler \& Polykoff (5) correlated the composition of a calcium oxalate stone crystallographically to that seen on a plain radiograph in an attempt to pre-operatively predict the fragility of $\mathrm{CaOx}$ stones. They described 4 patterns radiographically with a decreasing fraction of $\mathrm{CaOx}$ monohydrate content relative to the stone's $\mathrm{CaOx}$ dihydrate content. The most significant finding was that smooth, very radiodense stones were usually composed of $100 \%$ $\mathrm{CaOx}$ monohydrate, and did not respond well to SWL compared to the other 3 types of $\mathrm{CaOx}$ stones (5). Although clinical experience validates these results 
Table 2 - Stone composition of stone-free and non-stone-free patients. Values in table represent the number of patients with a particular major stone component.

\begin{tabular}{|c|c|c|c|c|c|c|c|c|c|}
\hline Group & $\begin{array}{l}\text { Stone } \\
\text { free }\end{array}$ & $\begin{array}{c}\text { Calcium } \\
\text { oxalate }\end{array}$ & $\begin{array}{c}\text { Calcium } \\
\text { oxalate } \\
\text { monohydrate }\end{array}$ & $\begin{array}{l}\text { Calcium } \\
\text { oxalate } \\
\text { dihydrate }\end{array}$ & $\begin{array}{l}\text { Calcium } \\
\text { phosphate }\end{array}$ & $\begin{array}{l}\text { Uric } \\
\text { acid }\end{array}$ & Cystine & Struvite & Total \\
\hline \multirow[t]{2}{*}{1} & Yes & 6 & 28 & 2 & 0 & 0 & 0 & 1 & 37 \\
\hline & No & 3 & 6 & 2 & 0 & 0 & 0 & 0 & 11 \\
\hline \multirow[t]{2}{*}{2} & Yes & 4 & 12 & 4 & 1 & 0 & 0 & 0 & 21 \\
\hline & No & 0 & 5 & 1 & 0 & 0 & 0 & 0 & 6 \\
\hline \multirow[t]{2}{*}{3} & Yes & 9 & 20 & 7 & 1 & 0 & 0 & 1 & 38 \\
\hline & No & 1 & 16 & 3 & 1 & 0 & 0 & 1 & 22 \\
\hline \multirow[t]{2}{*}{4} & Yes & 1 & 11 & 3 & 1 & 1 & 0 & 0 & 17 \\
\hline & No & 0 & 4 & 0 & 0 & 1 & 1 & 0 & 6 \\
\hline $\begin{array}{l}\text { Total } \\
(\%)\end{array}$ & & $\begin{array}{c}24 \\
(15)\end{array}$ & $\begin{array}{l}102 \\
(65)\end{array}$ & $\begin{array}{c}22 \\
(14)\end{array}$ & $\begin{array}{c}4 \\
(3)\end{array}$ & $\begin{array}{c}2 \\
(1)\end{array}$ & 1 & $\begin{array}{c}3 \\
(2)\end{array}$ & 158 \\
\hline
\end{tabular}

for stones $>2 \mathrm{~cm}$, there is scant data regarding the success of SWL for stones $\leq 2 \mathrm{~cm}$ based on its radiographic appearance. Furthermore, because of the various other stone parameters that affect the efficacy of the SWL, such as stone size, stone location, and the type of lithotriptor machine used, the significance of stone density alone for stones $\leq 2 \mathrm{~cm}$ is unclear.

A review of the literature reveals only 2 clinical studies that have examined stone fragmentation based on the appearance of the stone on a plain radiograph $(2,3)$. Both these studies used a multivariate analysis approach to evaluate various stone parameters (stone size, shape, location, and radiodensity) and clinical outcomes, rather than controlling for each parameter specifically. In a study by Bon et al. (2), rough, less dense calculi achieved a $79.4 \%$ stone free rate (SFR), while smooth, dense calculi had a $33.6 \%$ SFR using the Sonolith 3000 machine. In the study by Aeberli et al. (3), no correlation between stone radiodensity and disintegration was noted using the Dornier HM-3 machine. Unfortunately, results were not stratified according to stone size and stone location in either of these reports.
As CT has become the most common imaging modality for evaluating patients with renal colic, several studies have examined whether CT attenuation values can be used to predict stone composition and fragility (6-16). The premise with the identification of stone composition by $\mathrm{CT}$ attenuation values has been that if knowledge of the stone composition can be predicted prior to SWL, this information would directly correlate to stone fragility. Unfortunately, the fragility of stones with the same composition can itself be unpredictable for stones containing calcium (17).

The CT attenuation value of kidney stones is affected by several factors: stone size, stone composition, the energy of the CT camera, and the slice thickness (collimation) used to image the stone (4). Although the CT attenuation values at small collimation (1 to $3 \mathrm{~mm}$ ) have better predictability of stone composition in-vitro (4), the clinical usefulness of 5 mm collimation to predict stone fragility is unknown. Uric acid calculi may be differentiated from calcium stones based on their hounsefield units, but this distinction can also be made with knowledge of a stone's radiodensity and urinary $\mathrm{pH}$. 
Fluoroscopic imaging and fluoroscopic stone targeting remains a major component of SWL application currently. As such, a KUB is often required pre-operatively to plan lithotripsy treatment. The appearance of a stone on a KUB (size, shape, and radiodensity) is often used to predict the success of therapy (5). However, compared with other stone characteristics, the relative importance of stone radiodensity in predicting treatment outcome remains to be proved.

In the present study, we grouped stones according to stone radiodensity and size. We controlled for stone location by choosing stones only within the renal pelvis at the time of the SWL. We only included patients with a solitary stone less than or equal to $2 \mathrm{~cm}$. All stones were evaluated on a plain radiograph and categorized based on their radiodensity relative to the $12^{\text {th }}$ rib. Follow-up on all patients was available and SFR was determined with a KUB performed by the referring urologist. The reliability of this information submitted by the referring urologist has been confirmed in one of our previous studies (18).

Our results show no statistically significant differences in SFR for stones of different sizes based on radiodensity alone. However, stones which were between 11-20 $\mathrm{mm}$ and were more radiodense than the $12^{\text {th }}$ rib (Group 3) tended to have a worse outcome $(60 \%$ SFR) when compared to stones that were less radiodense than the $12^{\text {th }}$ rib (Group $4,71 \%$ ). The power index did not differ significantly between the different groups, although a higher power index was used for stones $11-20 \mathrm{~mm}$ in size and more radiodense than the $12^{\text {th }}$ rib. Almost two-thirds of the stones analyzed had calcium oxalate monohydrate as the major stone component (Table-2). The radiodensity of the stone was not predictive of the stone composition.

The approximately $70 \%$ SFR reported for the Doli machine with general anesthesia for renal pelvic stones $<2 \mathrm{~cm}$ is lower than the $88 \%$ SFR for all kidney stones on this machine (18) previously reported by us. The major difference between our previous study (besides being conducted over different time periods) and the current study is that we had $100 \%$ follow-up data available for the current study compared to $62 \%$ follow-up data available for the previous study. As such, we feel that the 70\% 3-month SFR for stones $<2 \mathrm{~cm}$ is a more accurate assessment of this machine's efficacy.

Our study suggests that for stones $<2 \mathrm{~cm}$ within the renal pelvis, the value of radiographic appearance of a stone alone in determining treatment outcome on the Doli machine is somewhat limited. There seems to be a tendency for a worse outcome for stones between 11-20 $\mathrm{mm}$ that have a radiodensity greater than the $12^{\text {th }}$ rib. The significance of this parameter may be more prominent if the stone size exceeds $2 \mathrm{~cm}$ or if the stone is located in a lower pole calyx. Our study did not examine SWL efficacy based on a stone's contour. The stone's smoothness and uniformity of density are qualitative assessments that probably affect outcome but are difficult to quantify.

\section{CONCLUSION}

For renal pelvic stones less than $1 \mathrm{~cm}$, stone radiodensity alone, as determined by a KUB, is not predictive of SWL success with the Doli machine. However, the stone's increased radiodensity may be an indicator of a worse SWL outcome when the stone size exceeds $1 \mathrm{~cm}$. This information may be used to counsel patients and select alternative treatment options when the stone size exceeds $1 \mathrm{~cm}$ and the stone radiodensity exceeds that of the $12^{\text {th }}$ rib.

\section{REFERENCES}

1. Dretler SP: Editorial comment. Urology. 2003; 61: 1097.

2. Bon D, Dore B, Irani J, Marroncle M, Aubert J: Radiographic prognostic criteria for extracorporeal shockwave lithotripsy: a study of 485 patients. Urology. 1996; 48: 556-60; discussion 560-1.

3. Aeberli D, Miller S, Schmutz R, Schmid HP: Predictive value of radiological criteria for disintegration rates of extracorporeal shock-wave lithotripsy. Urol Int. 2001; 66: 127-130.

4. Saw KC, McAteer JA, Fineberg NS, Monga AG, Chua GT, Lingeman JE, et al.: Calcium stone fragility is predicted by helical CT attenuation values. J Endourol. 2000; 14: 471-4. 
5. Dretler SP, Polykoff G: Calcium oxalate stone morphology: fine tuning our therapeutic distinctions. J Urol. 1996; 155: 828-33.

6. Mostafavi MR, Ernst RD, Saltzman B: Accurate determination of chemical composition of urinary calculi by spiral computerized tomography. J Urol. 1998; 159: 673-5.

7. Joseph P, Mandal AK, Singh SK, Mandal P, Sankhwar SN, Sharma SK: Computerized tomography attenuation value of renal calculus: can it predict successful fragmentation of the calculus by extracorporeal shock wave lithotripsy? A preliminary study. J Urol. 2002; 167: 1968-71.

8. Dretler SP, Spencer BA: CT and stone fragility. J Endourol. 2001; 15: 31-6.

9. Newhouse JH, Prien EL, Amis ES Jr, Dretler SP, Pfister RC: Computed tomographic analysis of urinary calculi. AJR Am J Roentgenol. 1984; 142: 545-8.

10. Hillman BJ, Drach GW, Tracey P, Gaines JA: Computed tomographic analysis of renal calculi. AJR Am J Roentgenol. 1984; 142: 549-52.

11. Motley G, Dalrymple N, Keesling C, Fischer J, Harmon $\mathrm{W}$ : Hounsfield unit density in the determination of urinary stone composition. Urology. 2001; 58: 170-3.

12. Federle MP, McAninch JW, Kaiser JA, Goodman PC,
Roberts J, Mall JC: Computed tomography of urinary calculi. AJR Am J Roentgenol. 1981; 136: 255-8.

13. Kuwahara M, Kageyama S, Kurosu S, Orikasa S: Computed tomography and composition of renal calculi. Urol Res. 1984; 12: 111-3.

14. Mitcheson HD, Zamenhof RG, Bankoff MS, Prien EL: Determination of the chemical composition of urinary calculi by computerized tomography. J Urol. 1983; 130: 814-9.

15. Nakada SY, Hoff DG, Attai S, Heisey D, Blankenbaker D, Pozniak M: Determination of stone composition by noncontrast spiral computed tomography in the clinical setting. Urology. 2000; 55: 816-9.

16. Saw KC, McAteer JA, Monga AG, Chua GT, Lingeman JE, Williams JC Jr: Helical CT of urinary calculi: effect of stone composition, stone size, and scan collimation. AJR Am J Roentgenol. 2000; 175: 329-32.

17. Williams JC Jr, Saw KC, Paterson RF, Hatt EK, McAteer JA, Lingeman JE: Variability of renal stone fragility in shock wave lithotripsy. Urology. 2003; 61: 1092-6; discussion 1097.

18. Sorensen C, Chandhoke P, Moore M, Wolf C, Sarram A: Comparison of intravenous sedation versus general anesthesia on the efficacy of the Doli 50 lithotriptor. $\mathbf{J}$ Urol. 2002; 168: 35-7.

Received: November 24, 2004 Accepted: January 7, 2005

\author{
Correspondence address: \\ Dr. Paramjit Chandhoke \\ University of Colorado Health Sciences Center \\ 4200 E. 9th Ave., Box C-319 \\ Denver, Colorado, 80262, USA \\ Fax: + 1303 315-7611 \\ E-mail:pj.chandhoke@uchsc.edu
}




\section{EDITORIAL COMMENT}

The authors should be congratulated in their attempt utilize stone density assessment, based on plain abdominal radiographs to predict stone-free rates following shock wave lithotripsy. While no significant correlation was achieved between the various groups, there appeared to be a trend towards lower stone-free rates with calculi of "higher density," that were greater than $1 \mathrm{~cm}$ in diameter.

There is no question that our ability to predict stone composition prior to initiating surgical therapy will greatly enhance the Urologist's ability to provide the optimal treatment for a specific patient. Knowing pre-operatively that a likelihood of successful SWL-based therapy is significantly re- duced by assessing a stone composition will direct the urologist and patient to choose a more efficient mode of stone removal.

Ideally, utilizing a plain abdominal radiograph to predict stone composition would be ideal as this is the most commonly used imaging modality, prior to initiating stone therapy. However, this imaging exam may not be sensitive enough to appropriately predict stone composition. Further studies are indeed warranted to enable more accurate prediction of stone composition prior to initiating stone therapy, since if successful, appropriate resources can be better utilized to provide effective and efficient outcomes for the removal of symptomatic renal and ureteral calculi.

Dr. Glenn M. Preminger Comprehensive Kidney Stone Center Duke University Medical Center Durham, North Carolina, USA 